Revta brasil. Bot., São Paulo, V.23, n.4, p.421-425, dez. 2000

\title{
Biologia floral de Unonopsis guatterioides (A. D.C.) R.E. Fr., uma Annonaceae polinizada por Euglossini
}

\author{
RAQUEL CARVALHO ${ }^{1}$ e ANTONIO C. WEBBER ${ }^{2,3}$
}

(recebido em 23 de fevereiro de 2000; aceito em 16 de agosto de 2000)

RESUMO - (Biologia floral de Unonopsis guatterioides (A.DC.) R.E.Fr., uma Annonaceae polinizada por Euglossini). A biologia floral e a polinização por abelhas Euglossini de uma Annonaceae é descrita pela primeira vez e as adaptações a esse modo de polinização são comparadas às de outras espécies da família, que é predominantemente polinizada por coleópteros. A espécie Unonopsis guatterioides foi estudada em dois fragmentos de mata de terra firme no município de Manaus (AM). As flores são protogínicas e permanecem abertas expondo os estigmas e estames durante a antese que ocorre entre dois dias. São visitadas por machos de Eulaema bombiformis (Euglossini) que coletam o odor o qual se assemelha ao de "capim cidreira" (Andropogum nardus L.). Visitas de abelhas Meliponidae e coleópteros Chrysomelidae também foram registradas. Unonopsis guatterioides apresenta dicogamia sincronizada.

ABSTRACT - (Floral biology of Unonopsis guatterioides (A. DC.) R.E. Fr. an Annonaceae pollinated by Euglossini). The floral biology and pollination by Euglossini bees of an Annonaceae is described for the first time and the adaptations to this mode of pollination are compared with other Annonaceae species that are mainly pollinated by beetles. Unonopsis guatterioides was studied in two "terra firme" forest fragments at the municipality of Manaus (AM). The flowers are protogynous and, remain open during whole anthesis which occurs in two days exposing completely both stigma and stamens. The flowers are visited by male of Eulaema bombiformis (Euglossini) which collect the floral scent; visits of Meliponidae bees and Chrysomelidae beetles were also registered. Unonopsis guatterioides shows synchronous dichogamy.

Key words - Annonaceae, floral biology, pollination, Euglossini, Amazon

\section{Introdução}

Os representantes da família Annonaceae são em sua grande maioria polinizados por coleópteros de diferentes grupos (Gottsberger 1970, 1989, Norman \& Clayton 1986, Webber \& Gottsberger 1993, Küchmeister et al. 1998). Esses insetos se alimentam de pólen e tecidos nutritivos das pétalas e usam as flores como abrigo e local de cópula (Gottsberger 1989, Webber \& Gottsberger 1993, Webber 1996). Essas flores, em geral, formam uma câmara por ocasião da antese, devido à imbricação ou justaposição das pétalas. Algumas espécies têm Thysanoptera como polinizadores (Gottsberger 1994, Webber \& Gottsberger 1995); Nagamitsu \& Inoue (1997) reportam também Blattodea como polinizadores de uma espécie de Annonaceae. Essas flores polinizadas por esses insetos, também têm pétalas justapostas e não expõem estigmas e estames.

1. Programa de pós-graduação em Biologia Vegetal - Universidade Federal de Pernambuco. e-mail: rorchidacea@yahoo.com.br

2. Departamento de Biologia da Universidade do Amazonas, Estrada do Contorno, 3000, 69077-000 Manaus, AM, Brasil.

3. Autor para correspondência: awebber@ fua.br
Abelhas da família Meliponidae também visitam as flores de Annonaceae apenas quando estas estão liberando pólen, mas não têm papel na polinização, pois não podem entrar em contato com os estigmas quando estes estão receptivos (Webber 1982, 1996, Olesen 1992).

O presente trabalho descreve a biologia floral de Unonopsis guatterioides (A. DC.) R.E. Fr., uma Annonaceae com flores que expõem seus estigmas e estames durante toda a antese e é polinizada por machos de uma espécie de abelha da tribo Euglossini. Esse modo de polinização, difere muito dos padrões já descritos para essa família, polinizada predominante por coleópteros.

\section{Material e métodos}

As observações mais freqüentes foram realizadas entre os meses de setembro de 1998 e fevereiro de 1999, além de observações adicionais que se estenderam até setembro de 1999. Unonopsis guatterioides ocorre em vegetação de baixio com solo areno-argiloso e foi estudada em dois fragmentos de mata de terra firme, na área do Campus da Universidade do Amazonas e no $\mathrm{km}$ 8 da BR-174 (Manaus-Caracaraí). Ao todo foram marcados 24 indivíduos, para os quais foram anotados a altura e o DAP (diâmetro à altura do peito). Foram depositadas exsicatas da espécie no Herbário da Universidade do Amazonas (A. Webber \& S. Silva 1883). As observações foram inicialmente realizadas em diferentes horários, pela manhã, à tarde e à noite até verificação do período de antese das flores e da atividade dos insetos visitantes. 
Após este período inicial as observações foram concentradas entre 00:00 h e 10:00 h da manhã.

Foram registrados os horários de abertura das flores, de emissão de odor, período de receptividade dos estigmas e liberação de pólen A localização dos osmóforos foi determinada com vermelho neutro, pelo método descrito em Vogel (1990) e a coloração das flores foi determinada pela tabela de cores de Kornerup \& Wanscher (1981). Para verificar a ocorrência de auto-polinização espontânea ou apomixia, foram isolados 10 botões florais. Também foram registrados os insetos visitantes, seu horário de visitas e comportamento. Foram coletados exemplares dos insetos visitantes, exceto das abelhas consideradas pilhadoras. A abelha polinizadora foi identificada pelo Dr. Francisco Peralta e exemplares dela foram incluídos na coleção do Departamento de Entomologia do INPA.

\section{Resultados}

Caracterização dos indivíduos, das flores e frutos Os indivíduos de Unonopsis guatterioides ocorrem nas proximidades de igarapés sobre solo areno argiloso, são arvoretas ou árvores com altura de 4,5 a $10,0 \mathrm{~m}$, e DAP de 3,5 a $5,0 \mathrm{~cm}$, às vezes formando touceiras. As flores (figura 1A) ocorrem isoladas ou menos freqüentemente em inflorescências paucifloras, sobre ramos primários e secundários em posição pendente a lateralmente inclinada. As flores são trímeras, com dois verticilos de pétalas, as do verticilo externo apresentando um indumento ao longo da porção mediana no sentido longitudinal. Os estames são numerosos (172 a 236) e os carpelos variam de sete a 12 , contendo de dois a quatro óvulos. Os botões quando maduros são cilíndricos e assim como as flores são de coloração amarelo claro (3 a 4) segundo a tabela. Os frutos são apocárpicos com carpídios baciformes estipitados (figura 1D).

Biologia floral - Unonopsis guatterioides possui flores protogínicas que apresentam dicogamia sincronizada, com flores ou na fase feminina, ou masculina, num mesmo dia, no mesmo indivíduo. Dos 24 indivíduos observados, apenas um apresentou uma vez flores na fase feminina e uma flor na fase masculina num mesmo dia.

Alguns botões apresentam uma pequena abertura, um ou dois dias antes da antese e outros permanecem completamente fechados até o momento em que esta se inicia. O início da abertura ocorre após às 02:00 h, de modo lento. Algumas vezes, os botões já liberam odor, mas a abertura total das flores é sempre precedida pela sua liberação. As flores quando se abrem expõem os estigmas, já receptivos, cobertos por uma substância pegajosa, e os estames já que as pétalas ficam bem afastadas. Na fase feminina inicial, as flores permanecem liberando odor intenso que se assemelha ao das folhas de capim cidreira (Andropogum nardus L., Poaceae) mas pode assumir cheiro de baunilha, nos horários em que se torna menos intenso. $\mathrm{O}$ odor pode ser sentido até 08:30-09:00 h, quando cessa sua emissão. Na madrugada seguinte, inicia-se novamente a emissão de odor, quando as flores começam a entrar na fase masculina, com os estames começando a liberar o pólen. O início da liberação de pólen ocorre entre 03:00 e 06:00 h, após queda dos estigmas, que se tornam um pouco escurecidos e secos. A liberação de pólen inicialmente é lenta, da base em direção ao ápice, depois acelera-se por volta de 05:00 h, estendendo-se no máximo até 06:30 h. Os estames permanecem temporariamente ligados ao receptáculo (figura 1B) por minúsculas estruturas filiformes que são reforços espiralados de vasos xilemáticos. Após a liberação total do pólen, as flores começam a perder suas peças florais, por volta das 08:00 h terminando próximo de 09:00 h. A liberação de odor é sincrônica entre flores de ambas as fases. Os osmóforos localizam-se na porção central externa das pétalas do verticilo externo. No máximo quatro flores são encontradas abertas por dia, num mesmo indivíduo.

A queda dos estigmas, antes da liberação do pólen, impede a ocorrência da autopolinização e a geitonogamia é dificultada pela dicogamia sincronizada. Há indícios de que a espécie não apresenta autopolinização espontânea nem apomixia.

Insetos visitantes - As flores de Unonopsis guatterioides são visitadas por abelhas macho de Eulaema bombiformis (Euglossini) (figura 1C) e Meliponidae e coleópteros Chrysomelidae. As Euglossini, ao se aproximarem das flores em antese em sua fase inicial ou final, permanecem primeiro pairando no ar em frente a estas e em seguida, pousam e pairam sucessivas vezes. Ao pousar sobre as flores, agarram-se às pétalas do verticilo externo, estabelecendo contato muito rápido (10 a $20 \mathrm{~s}$ ), onde o abdômen toca os estigmas e estames. Quando a flor está liberando pólen, este adere facilmente aos pêlos do corpo e das patas. As abelhas coletadas possuíam pólen no corpo, porém este não foi analisado para verificar se procedia somente da espécie estudada. 

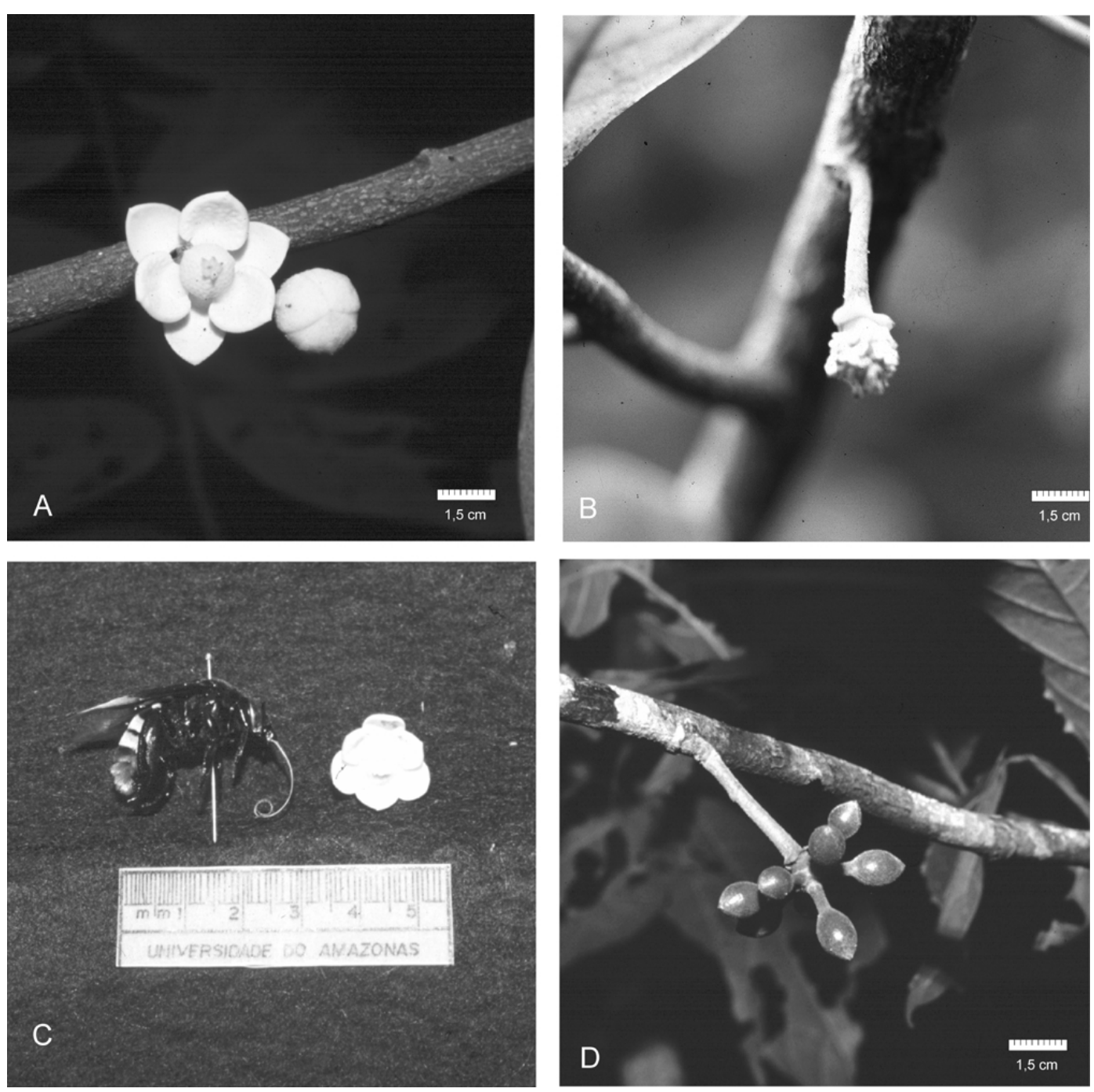

Figura 1. Unonopsis guatteriodes. A - flor no primeiro dia de antese com os estigmas receptivos no centro, B - estames presos ao receptáculo floral após a queda das pétalas, C - flor e visitante Eulaema bombiformis, D - fruto com carpídios baciformes imaturos.

Essas abelhas visitam diferentes flores no mesmo indivíduo e em diferentes indivíduos.

As abelhas Meliponidae visitam as flores após às 06:30 $\mathrm{h}$, permanecem sobrevoando as flores que estão na fase feminina ou na masculina e, eventualmente, pousam nessas, onde coletam pólen. Os Crisomelídeos visitam as flores tanto durante o dia quanto durante a noite e permanecem em grande quantidade nas flores, raspando o tecido das partes internas das pétalas.

\section{Discussão}

As flores de Unonopsis guatterioides permanecem abertas, com as pétalas bem afastadas, expondo bem os seus estigmas e estames. Esse afastamento das pétalas contrasta muito com outras espécies que apresentam flores fechadas, pela justaposição ou imbricação das pétalas, onde os visitantes precisam forçar sua entrada, como por exemplo em Annona (Gottsberger 1989) Cymbopetalum (Webber \& Gottsberger 1993) ou Duguetia (Webber 1996). Essa 
exposição dos estigmas e estames, permite facilmente às abelhas visitantes entrar em contato tanto com os estigmas receptivos, como com os estames, quando esses estão liberando pólen. Os estames permanecem temporariamente presos ao receptáculo por estruturas filiformes, possibilitando que o pólen fique exposto por um maior tempo aos visitantes, com ocorre em outras Annonaceae (Endress 1985).

O odor emitido pelas flores lembra o de capim cidreira e em certos horários o de baunilha e parece ser a recompensa aos machos das abelhas Euglossinae que as visitam. A emissão de odor é sincrônica entre flores receptivas e flores que estão liberando pólen, o que permite que elas sejam visitadas indistintamente. As flores de Unonopsis stipitata Diels emitem odor semelhante ao de hortelã (A.C. Webber, dados não publicados). O odor emitido por essas duas espécies do gênero Unonopsis, difere bastante daquele emitido pelas flores que são polinizadas por coleópteros (Gottsberger 1990). A localização dos osmóforos na face externa das pétalas difere das outras espécies de Annonaceae estudadas, nas quais essas estruturas se localizam sempre na face interna. A localização dos osmóforos parece ser uma adaptação que facilita a coleta do odor pelas abelhas. O odor é considerado o principal modo de atração dos polinizadores às flores das Annonaceae que apresentam um variado espectro de odores (Gottsberger 1990, Webber 1996). Em Unonopsis guatterioides, além de atração, o odor representa também a recompensa, uma vez que os machos das abelhas provavelmente o usam como ingrediente na produção de feromônios (Williams \& Whitten 1983).

As abelhas Euglossinae, que coletam odor nas flores representam um grupo muito importante de polinizadores de Orchidaceae de um modo geral e, espécies das sub-tribos Catassetinae e Stanhopeinae, apresentam estreita relação específica com essas abelhas (Dressler 1968, Williams \& Whitten 1983, Chase \& Hills 1992).

Além de Orchidaceae, essas abelhas também coletam odor e polinizam Dalechampia spathulata, Euphorbiaceae (Armbuster \& Webster 1979) e espécies de outras famílias como Araceae, Gesneriaceae e Solanaceae (Williams \& Whitten 1983). Zucchi et al. (1969) apresentam uma lista de famílias que têm representantes visitadas por Euglossini onde agora as Annonaceae também se incluem.
As abelhas Meliponidae podem ser consideradas pilhadoras de pólen, como fazem em outras espécies da família (Webber 1982, 1996) e não participam da polinização pois elas só visitam as flores que estão liberando pólen.

Os Chrysomelidae que visitam as flores aparentemente não têm papel na polinização, sendo apenas predadores que às vezes causam sérios prejuízos às flores. Miralha (1995) também registra a visita desses coleópteros às flores de Unonopsis stipitata e presume que estes são os polinizadores dessa espécie. Esses coleópteros talvez sejam apenas predadores, já que abelhas Euglossini visitam as flores dessa espécie (Webber, dados não publicados).

Em Unonopsis guatterioides, a queda dos estigmas antes da liberação do pólen impede a autopolinização, o que ocorre em outros representantes da família (Webber 1982, Webber \& Gottsberger 1993). Além disso, parece haver uma tendência a evitar a polinização geitonogâmica através de um sincronismo, no qual num mesmo indivíduo, num mesmo dia, ou são produzidas flores que estão iniciando a antese ou, são produzidas flores que a estão encerrando. Essa dicogamia sincronizada ocorre em outras Annonaceae (Webber 1982, 1996, Murray \& Johnson 1987). Cruden (1988) define este comportamento como um dioicismo temporal e o interpreta como uma alternativa evolutiva à autoincompatibilidade.

A família Annonaceae é tida como uma das primitivas dentre as Magnoliophyta e a cantarofilia é uma das características partilhadas por grande parte dos membros da família. Até o presente, não havia registros de espécies dessa família polinizadas por abelhas Euglossini. O registro da polinização de uma Annonaceae por Eulaema bombiformis amplia os modos de polinização descritos por Gottsberger (1993) e mostra que numa família mais basal há um modo de polinização freqüente em famílias mais derivadas.

\section{Referências bibliográficas}

ARMBRUSTER, S.W. \& WEBSTER, G.L. 1979. Pollination of two species of Dalechampia Euphorbiaceae in Mexico by Euglossine bees. Biotropica 11:278-283. 
CHASE, M.W. \& HILLS, H.G. 1992. Orchid phylogeny, flower sexuality and fragrance seeking. Evidence from variation in chloroplast DNA among subtribes Catasetinae and Cyrtopodiinae. Bioscience 42:43-49.

CRUDEN, R.W. 1988. Temporal dioecism: systematic breadth, associated traits, and temporal patterns. Botanical Gazette 149:1-15.

DRESSLER, R.L. 1968. Observations on orchids and Euglossinae bees in Panama and Costa Rica. Revista de Biologia Tropical 15:143-183.

ENDRESS, P.K. 1985. Stamenabszission und Pollenpräsentation bei Annonaceae. Flora 176:95-98.

GOTTSBERGER, G. 1970. Beiträge zur Biologie von Annonaceenblüten. Österreichiche Botanisches Zeitschrift 118:237-279.

GOTTSBERGER, G. 1989. Beetle pollination and flowering rhythm of Annona spp. (Annonaceae) in Brazil. Plant Systematics and Evolution 167:165-187.

GOTTSBERGER, G. 1990. Pollination and flower evolution in neotropical Annonaceae. Annonaceae Newsletter 8:35-36.

GOTTSBERGER, G. 1993. Flower biological differentiation in neotropical Annonaceae. Annonaceae Newsletter 9:29-33.

GOTTSBERGER, G. 1994. As Anonáceas do cerrado e sua polinização. Revista Brasileira de Biologia 54:391-402.

KORNERUP, A. \& WANSCHER, J.H. 1981. Taschenlexikon der Farben. Musterschmidt Verlag, Zürich.

KÜCHMEISTER, H., WEBBER, A.C., SILBERBAUER, I. \& GOTTSBERGER, G. 1998. A polinização e sua relação com a termogênese em espécies de Arecaceae e Annonaceae da Amazônia Central. Acta Amazonica 28:217-245.

MIRALHA, J.M. de S. 1995. As Annonaceae da Reserva Florestal Ducke, Manaus, AM. Tese de doutorado, INPA/FUA, Manaus.

MURRAY, N.A. \& JOHNSON, D.M. 1987. Synchronous dichogamy in a Mexican anonillo Rollinia jimenezii var. nelsonii Annonaceae. Contributions from the University Michigan Herbarium 16:173-178.
NAGANITSU, T. \& INOUE, T. 1997. Cockroach pollination and breeding system of Ulvaria elmeri (Annonaceae) in a lowland mixed dipterocarp forest in Sarawak. American Journal of Botany 84:208-213.

NORMAN, E.M. \& CLAYTON, D. 1986. Reproductive Biology of two Florida pawpaws: Asimina obovata and A. pygmaea (Annonaceae). Bulletin of the Torrey Botanical Club 113:16-22.

OLESEN, J.M. 1992. Flower mining by moth larvae vs. pollination by beetles and bees in the cauliflorous Sapranthus palanga (Annonaceae) in Costa Rica. Flora 187:9-15.

VOGEL, S. 1990. The role of scent glands in pollination. A.A. Balkema, Rotterdam.

WEBBER, A.C. 1982. Biologia floral de Rollinia mисоsa (Jacq.) Baill. (Annonaceae). Anais do XXXIII Congresso Nacional de Botânica: 57-63.

WEBBER, A.C. 1996. Biologia floral, polinização e fenologia de algumas Annonaceae na região de Manaus AM. Tese de doutorado, INPA/FUA, Manaus.

WEBBER, A.C. \& GOTTSBERGER, G. 1993. Floral biology and pollination of Cymbopetalum euneurum (Annonaceae) in Manaus, Amazonia. Annonaceae Newsletter 9:25-28.

WEBBER, A.C. \& GOTTSBERGER, G. 1995. Floral biology and pollination of Bocageopsis multiflora and Oxandra euneura in Central Amazonia, with remarks on the evolution of stamens in Annonaceae. Feddes Repertorium 106:515-524.

WILLIAMS, N.H. \& WHITTEN, W.M. 1983. Orchid floral fragrances and male euglossine bees: methods and advances in the last sesquidecade. Biological Bulletin 164:355-395.

ZUCHII, R., SAKAGAMI, S.F. \& CAMARDO, J.M.F. 1969. Biological observations on a neotropical parasocial bee, Eulaema nigrita, with a review on the biology of Euglossinae (Hymenoptera, Apidae). A comparative study. Journal of the Faculty of Science Hokkaido University VI Zoology 17:271-380 